\title{
O MECANISMO DE ANTECIPAC̣ÃO APLICADO À ANÁLISE DISCURSIVA DE ENTREVISTAS: IMAGINÁRIOS DE LEITURA DE PROFESSORES NA EDUCAÇÃO CIENTÍFICA ${ }^{1}$
}

\begin{abstract}
RESUMO: Considerando a importância da entrevista na tomada de dados em um grande número de pesquisas na área de educação em ciências, apresentamos e discutimos contribuições teórico-metodológicas da noção de mecanismo de antecipação, da Análise do Discurso francesa, para a análise de entrevistas. Compreendendo discurso como efeito de sentidos entre interlocutores, em que jogam relações de força, de sentidos e mecanismos imaginários como condições de produção, essa noção ressalta a importância da consideração do contexto imediato da entrevista e das expectativas e representações entre os interlocutores como constitutivas da produção dos dizeres dos entrevistados. Possibilita trabalhar a relação entre contexto imediato e contexto histórico-social mais amplo, importante quando se deseja compreender os processos de dizer como parte do funcionamento social e político. Analisamos entrevistas com professores sobre leitura na educação científica em que são evidenciados aspectos desse mecanismo de antecipação mobilizando diferentes relações imaginárias, socialmente constituídas, entre entrevistador (pesquisador) e entrevistados (professores).
\end{abstract}

Palavras-chave: Mecanismo de antecipação. Entrevista. Leitura.

\section{INTERVIEWS: TEACHERS' READING IMAGINARIES IN SCIENCE EDUCATIONTHE ANTICIPATION MECHANISM APPLIED TO DISCOURSIVE ANALYSIS OF}

ABSTRACT: In this paper we discuss theoretical and methodological contributions of a concept of the French Discourse Analysis, the Anticipation Mechanism, to interviews analysis. Understanding discourse as the effect of "signification/meaning exchange between interlocutors/speakers", in which power relations, meaning and imaginary mechanisms take place as production conditions, this notion emphasizes the importance of considering the immediate context of the interview, the expectations and mutual representations among speakers. Thus, interview contexts are considered as constitutive aspects of the respondent's utterances. This concept allows us study the relationship between immediate context and the broad historical-social context. This relationship is extremely important if we wish to comprehend language processes as part of the social and political contexts. We analyze interviews with teachers about reading in science education in which are highlighted aspects of this anticipation mechanism mobilizing different socially constituted imaginary relationships, between interviewer (researcher) and interviewed (teachers).

Keywords: Anticipation mechanism. Interview. Reading
Narjara Zimmermann*

Henrique César da Silva**

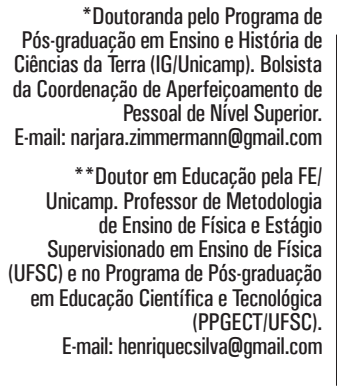

Pós-Doutoranda pelo Programa de Ciências da Terra (IG/Unicamp). Bolsista da Coordenação de Aperfeiçoamento de Pessoal de Nível Superior.

* *Doutor em Educacão pela FE Professor de Metodologia de Ensino de Física e Estágio ervisionado em Ensino de Fisica em e no Programa de Pós-graduação (PPGECT/UFSC).

E-mail: henriquecsilva@gmail.com 


\section{INTRODUCุão}

No cenário brasileiro da pesquisa em ensino de ciências, questões referentes à linguagem ganharam relevância nas últimas décadas. Os trabalhos apresentam, além de distintas perspectivas sobre linguagem (enunciativa, linguística, interacionista, discursiva, retórica, semiótica, textual discursiva, pragmático-discursiva, sociolinguística), direcionamentos diferentes sobre a forma como essas questões são desenvolvidas e incorporadas em pesquisas e como se relacionam com concepções de ensino, de ciência e de escola.

$\mathrm{Na}$ literatura, encontramos trabalhos cujo viés está centrado nas análises de construções conceituais em interações verbais orais em sala de aula (MORTIMER; SCOT'T, 2002), em que se dá relevância à relação constitutiva entre linguagem e pensamento e entre contexto e linguagem, através de metodologias que enfatizam a dimensão imediata e local da interação face a face. Também encontramos trabalhos que se apoiam em discussões sobre linguagem na relação com o ensino de ciências, enfocando a compreensão do funcionamento da leitura e do desempenho de textos escritos e/ou imagéticos em classe (MARTINS; NASCIMENTO; ABREU, 2004;SILVA;ALMEIDA, 2005), examinando materiais textuais em si, como livros didáticos (GIRALDI; SOUZA, 2006; MONTEIRO; JUSTI, 2000; MARTINS, 2006), ou analisando e refletindo sobre os discursos de ciência produzidos pelas diversas mídias (RAMOS; LINSINGEN; CASSIANI, 2008) em sua relação com educação científica. Entre os diversos fatores que sinalizam a diversidade de concepções teórico-metodológicas desses trabalhos, podemos apontar a amplitude com que se considera o contexto na sua relação com a linguagem. Isso tem implicações metodológicas importantes.

Embora a produção que focaliza a linguagem seja crescente, carecemos ainda de trabalhos que aprofundem e que se centrem em questões metodológicas, nos desafios, limites e potencialidades das diferentes perspectivas teórico-metodológicas. Dentre os trabalhos que têm se debruçado sobre discussões teórico-metodológicas relacionadas ao tratamento de dados de linguagem, podemos citar o de Moraes (2003) e o de Silva, Baena e Baena (2006), entre outros. E, ainda dentro desse conjunto, há aqueles que têm se centrado mais especificamente em questões teórico-metodológicas relacionadas à produção e à análise de entrevistas, como os de Almeida (2007) e Flôr e Souza (2008).

Este trabalho tem como foco a questão da produção e da análise de entrevistas, por considerarmos um dos instrumentos de pesquisa mais utilizados na área de educação científica e tecnológica.

Almeida (2007) já apontava a existência de diferentes possibilidades de uso desse instrumento, comentando que "as sínteses sobre as perspectivas dos autores até aqui citados (...) são suficientes para notarmos que possibilidades e limites do que se pode conseguir através de uma entrevista não podem ser dissociadas das concepções de linguagem de quem as enuncia" (p. 120).

Temos notado, de modo geral, que esses e outros estudos, como os de Andrade e Martins (2006), Cassab e Martins (2008) e Sepulveda e El-Hani (2006), 
evidenciam uma perspectiva de pesquisa cujas análises não buscam apenas "extrair" os "conteúdos" das falas e tomá-los como dados em si mesmos.

Na conclusão de seu artigo sobre essa problemática, Almeida (2007) assim sintetiza suas análises:

Entretanto, a consideração dos fragmentos de entrevistas examinados como discursos, na abordagem da análise de discurso em que nos apoiamos neste estudo, não supõe a possibilidade de as falas serem pesquisadas/investigadas detalhadamente enquanto dados que revelariam uma verdade transparente através do estudo. Aqui, os dados são os discursos (Orlandi, 1996), que não se constituem em objetos empíricos, mas sim em efeitos de sentidos entre locutores (p. 129).

As entrevistas, mesmo que a partir das diferentes perspectivas teórico-metodológicas adotadas nesses estudos, são pensadas não somente como um instrumento para comunicação de informações, ou melhor, para se "extrair" as informações de quem se deseja entrevistar. Esses trabalhos parecem ter em comum a ideia de que há um processo de significação do qual as sequências verbais produzidas e analisadas são o produto, e de que o contexto faz parte desse processo. Ou seja, o contexto possui uma relação constitutiva com a produção da sequência verbal analisada. Tal ideia, a nosso ver, está associada a uma concepção de linguagem como não transparente. Assim, trata-se de uma perspectiva em que as representações e expectativas entre os interlocutores, entrevistado e entrevistador são constitutivas dos processos e produtos das entrevistas e precisam, portanto, serem consideradas nas análises. Por constitutiva queremos dizer que, embora exterior à sequência verbal, é dimensão intrínseca do processo de significação (produção não subjetiva da interpretação) do qual aquela sequência verbal faz parte, dimensão sem a qual essa sequência não significa.

No entanto, os trabalhos desses mesmos autores se diferenciam quanto ao sentido que a noção de contexto adquire. Em alguns, o contexto se refere exclusivamente, ou mais enfaticamente, no momento das análises, à situação imediata e ao local de interação face a face. Em outros, como coloca Almeida (2007), referem-se a uma concepção de linguagem que "além de assumir a não-transparência da linguagem, alarga o conceito de discurso para além das situações imediatas, pela consideração do contexto sociohistórico” (p. 120).

De nossa parte, essa concepção e os encaminhamentos metodológicos que temos desenvolvido estão atrelados, na pesquisa com entrevistas, à noção de mecanismo de antecipação (ORLANDI, 1996; 2003). Mostramos como a noção de mecanismo de antecipação permite metodologicamente relacionar contexto imediato e contexto histórico-social mais amplo.

As discussões que apresentamos são particularmente relevantes quando se deseja, com as entrevistas, compreender o contexto no qual elas são realizadas, ou seja, as condições em que são produzidas as formulações e os discursos sobre um determinado assunto. Desse modo, para essas perspectivas de pesquisas, como foi o caso das análises que apresentamos como exemplo, o contexto também é 
parte do objeto de estudo, na relação que estabelece com os dizeres e os imaginários. Tais contextos possibilitariam/limitariam interpretações pelos sujeitos, ou seja, são suas condições de possibilidade que estão em jogo. Não nos interessa compreender apenas os "conteúdos" das falas dos entrevistados, ainda que consideremos que dependendo da problemática isso possa ser extremamente relevante por si só. Queremos compreender as condições de produção desses "conteúdos” e como eles aparecem como tais. Explicitamos, ainda, a possibilidade de compreender essas condições imediatas e locais como partes de condições histórico-sociais mais amplas.

Como exemplos de análises, selecionamos, do âmbito de um trabalho maior que buscou compreender o imaginário e os discursos de professores sobre leitura em ensino de ciências, trechos de entrevistas concedidas por quatro professores (de Biologia, Geografia, Química e Português) do Ensino Médio de uma mesma escola pública.

\title{
A NOCִÃO DE MECANISMO DE ANTECIPACุÃO NO CONTEXTO TEÓRICO DA ANÁLISE DE DISCURSO
}

\author{
Como observam Flôr e Souza (2008):
}

\begin{abstract}
A utilização da análise do discurso enquanto referencial analítico exige em grande parte sua incorporação como referencial teórico, pois se trata de lançar um olhar diferenciado à prática da pesquisa em um contexto de trabalho com material simbólico. Assim, sua utilização apenas como ferramenta de análise de dados empíricos impede a amplitude de olhar necessária a este tipo de trabalho (p. 14).
\end{abstract}

Nossa discussão e problematização da situação de entrevista se pautam nesse referencial teórico específico, notadamente em aportes da Análise do Discurso (doravante AD) iniciada por Michael Pêcheux, na década de 1960, na França, influenciado por Michel Foucault, e divulgada e desenvolvida no Brasil por Eni. P. Orlandi, além de outros autores. Essa perspectiva discursiva "não trata da língua, não trata da gramática, embora todas essas coisas lhe interessem. Ela trata do discurso. (...) O discurso é assim palavra em movimento, prática de linguagem: com o estudo do discurso observa-se o homem falando" (ORLANDI, 2003, p. 15).

Embora a AD não estacione na interpretação, buscando trabalhar seus limites e mecanismos, procurando compreender como as interpretações funcionam, como pesquisadores, ao nos filiarmos a essa concepção teórica de linguagem, reconhecemos nossa inescapável exposição ao simbólico e, portanto, à própria interpretação. Isso reflete na prescindibilidade de categorias fechadas para a análise, inteiramente pré-concebidas, assim como procedimentos lineares e reproduzíveis de análise de dados (SILVA; BAENA; BAENA, 2006). Expomo-nos, como pesquisadores, à abertura do simbólico e buscamos expô-la ao leitor, trabalhando a ideia pelo texto, e sobre os textos (sejam verbais, orais e escritos, ou imagéticos e 
audiovisuais), de que o sentido sempre pode ser outro, ainda que não qualquer um. Não há, para nós, oposição entre rigor e interpretação. Ou seja, admitimos que nossa análise, mesmo concluída, permanece aberta, posto que o simbólico não se fecha pela sua própria materialidade e pela sua relação com a memória, com a história. Se a $\mathrm{AD}$ não estanca na interpretação, ela também a admite como dimensão fundamental e inescapável da constituição de seus procedimentos analíticos.

Mas a abertura do simbólico é controlada. E, ao mesmo tempo em que é impossível fechá-la com a análise, pela própria análise busca-se mostrar em que parte se dá esse controle. Eis uma colocação interessante de Foucault (2004) nesse sentido:

Eis a hipótese que gostaria de apresentar esta noite, para fixar o lugar - ou o teatro muito provisório - do trabalho que faço: suponho que em toda a sociedade a produção do discurso é ao mesmo tempo controlada, selecionada, organizada e redistribuída por certo número de procedimentos que têm por função conjurar seus poderes e perigos, dominar seu acontecimento aleatório, esquivar sua pesada e temível materialidade (p. 9).

Sem nos esquivarmos da interpretação, admitindo a abertura permanente do simbólico, defendemos também que o sentido não pode ser qualquer um porque há controle. Desse modo, ao trabalhar essa tensão como constitutiva e constante de qualquer produção discursiva, justamente para compreendê-la num contexto específico de uma temática específica, é que vamos derivar certa noção de rigor que não se opõe à interpretação. E aí, citamos um dos textos de Pêcheux (1997) que, a nosso ver, melhor discute os procedimentos teórico-analíticos da AD:

Esse discurso-outro, enquanto presença virtual na materialidade descritível da sequência marca, do interior desta materialidade, a insistência do outro como lei do espaço social e da memória histórica, logo como o próprio princípio do real sócio-histórico. E é nisto que se justifica o termo de disciplina de interpretação, empregado aqui a propósito das disciplinas que trabalham esse registro (p. 55).

Essa perspectiva discursiva que adotamos visa compreender como um objeto simbólico (textos escritos, imagéticos, orais, audiovisuais, etc.) produz sentido, não apenas interpretando-o, mas explicitando como o texto encaminha seus gestos de interpretação (ORLANDI, 2003), sempre enquanto possibilidades. Para tal, a $\mathrm{AD}$ pressupõe a linguagem como produto do trabalho social e histórico do homem, por meio de um processo social-simbólico, colocando em evidência a opacidade da língua e de outros sistemas simbólicos ou semióticos, ou seja, buscando desfazer a própria transparência da linguagem. Entendemos, com isso, que o discurso, compreendido como efeitos de sentidos entre interlocutores, não se constitui independentemente do contexto. Ele está relacionado com condições de produção específicas, retomando, atualizando e deslocando outros dizeres.

É justamente como parte dessas condições de produção, ou ainda, como parte dos mecanismos que operam na tensão abertura-controle-fechamento que constituem os discursos, que o mecanismo de antecipação ganha sentido e relevância. 
Para a AD, "o sujeito significa em condições determinadas" (ORLANDI, 2003, p. 53), ou seja, pressupomos que os discursos analisados neste trabalho têm essas características porque foram produzidos em e por um conjunto de condições e não em outro. E esse pressuposto é o que define

grande parte do trabalho do analista: observando as condições de produção e verificando o funcionamento da memória, ele deve remeter, sempre que possível, o dizer a uma formação discursiva [o que pode e deve ser dito a partir de um lugar social historicamente determinado] para compreender o sentido do que ali está dito (ORLANDI, 2003, p. 45).

Os sujeitos e as situações de entrevistas configuram aspectos essenciais das condições de produção imediatas dos discursos produzidos. Em nosso caso, esses discursos estão baseados nas falas produzidas por quatro professores através de entrevistas semiestruturadas, uma vez que os discursos foram produzidos nessa relação, que consideramos única, entre entrevistado e entrevistador.

Falar em discurso é falar em condições de produção e, em relação a essas condições gostaríamos de destacar que, como exposto por Pêcheux (1979), são formações imaginárias ${ }^{2}$, e nessas formações contam a relação de forças ${ }^{3}$ (os lugares sociais dos interlocutores e sua posição relativa no discurso), a relação de sentido (o coro de vozes, a intertextualidade, a relação que existe entre um discurso e outros) $e$ a antecipação (a maneira como o locutor representa as representações de seus interlocutores e vice-versa) ${ }^{4}$ (ORLANDI, 1996, p. 158).

As condições de produção, além de englobarem o contexto imediato, também contemplam o contexto sócio-histórico, ou seja, as condições de produção no seu aspecto mais amplo e nas quais as próprias condições imediatas estão inseridas. E são essas condições que trariam para a consideração dos efeitos de sentidos elementos que derivam da nossa sociedade, produzidos por meio de um processo histórico e ideológico (ORLANDI, 2003), uma vez que esses discursos são produzidos num espaço/tempo e se relacionam com outros discursos produzidos em outros espaços/tempos, determinados social e historicamente. As condições imediatas representam uma das manifestações locais possíveis das condições de produção mais amplas, fazendo-as se constituírem ali, naquele momento-situação, com alguma singularidade. É nesse jogo entre contexto imediato e contexto mais amplo que a noção de mecanismo de antecipação pode contribuir nos processos de análise.

Dessa forma, "o saber discursivo que se foi constituindo ao longo da história e foi produzindo dizeres” (ORLANDI, 2003, p. 33) só se tornou possível de formulação pela existência da memória. Por isso, não teríamos como separar as condições de produção imediatas do seu contexto histórico, social e ideológico, já que

a constituição determina a formulação, pois só podemos dizer (formular) se nos colocamos na perspectiva do dizível (interdiscurso, memória). Todo dizer, na realidade, se encontra na confluência dos dois eixos: o da memória (constituição) e o da atualidade (formulação) (ORLANDI, 2003, p. 33). 
Memória e atualidade se cruzam na situação da entrevista que, de acordo com suas especificidades imediatas, fará o sujeito, inconscientemente, mobilizar esta ou aquela região do interdiscurso (memória discursiva).

Segundo Pêcheux (1993), o fato do discurso não ter rigorosamente um início e se sustentar sempre sobre um discurso prévio é que permite ao locutor experimentar antecipadamente o lugar do ouvinte, imaginando que efeito seus dizeres terão no ouvinte. "Essa antecipação do que o outro vai pensar parece constitutiva de qualquer discurso" (p. 77), e está relacionada, entre outros aspectos, ao próprio funcionamento das instituições nas quais os interlocutores atuam. Segundo Orlandi (2003):

Todo sujeito tem a capacidade de experimentar, ou melhor, de colocar-se no lugar em que o seu interlocutor 'ouve' suas palavras. Ele antecipa-se assim a seu interlocutor quanto ao sentido que suas palavras produzem. Esse mecanismo regula a argumentação, de tal forma que o sujeito dirá de um modo, ou de outro, segundo o efeito que pensa produzir em seu ouvinte. Este espectro varia amplamente desde a previsão de um interlocutor que é seu cúmplice até aquele que, no outro extremo, ele prevê como adversário absoluto. Dessa maneira, esse mecanismo dirige o processo de argumentação visando seus efeitos sobre o interlocutor (p. 39).

Assim, o mecanismo de antecipação é um dos mecanismos discursivos que, junto com as relações de força e as relações de sentido, está associado às formações imaginárias. Essa última noção nos lembra que não são dos sujeitos empíricos, sociologicamente descritíveis, que estamos tratando, mas de suas imagens que resultam de projeções da situação social da qual fazem parte. Desse modo, o mecanismo de antecipação permite trabalhar com essa situação social no "interior" dos discursos, revelando que o entrevistador não está fora da sociedade que produz o discurso que está buscando analisar e, portanto, não pode se colocar para fora da interpretação por meio de sua própria análise.

\section{CONDIC̣ÕES DE PRODUÇÃO DAS ENTREVISTAS REALIZADAS: CONTRIBUICְÕES DO MECANISMO DE ANTECIPAC̣ÃO}

Recortamos como exemplo de análise trechos de uma pesquisa mais ampla (ZIMMERMANN, 2008) cujo foco referia-se à compreensão de alguns aspectos das condições de produção dos discursos e imaginários de professores sobre leitura no ensino de ciências. Destacamos aqui mais fortemente seus aspectos imediatos, buscando evidenciar que estes só são possíveis se integrados a um processo mais amplo, entrando em jogo instituições como a escola, a universidade e os órgãos públicos do governo estadual e federal (como Secretarias de Educação e Ministério da Educação), bem como a própria ciência, como partes do funcionamento da sociedade em que vivemos, e implicadas na constituição de lugares sociais. 
Os quatro professores entrevistados, formados em Química (PQ), Geografia (PG), Português (PP) e Biologia (PB) trabalhavam na mesma escola pública estadual de um município do interior do estado de São Paulo e apresentavam algumas especificidades: participavam de um projeto de pesquisa colaborativa envolvendo conhecimentos do campo das Geociências junto com pesquisadores da universidade e de outros órgãos de pesquisa; estavam concluindo cursos de formação continuada disponibilizados pela Secretaria de Educação do Estado de São Paulo (SEESP), que foram realizados na escola e que tematizavam a leitura em todas as disciplina, Ensino Médio em Rede (EMR) e Práticas de Leitura e Escrita (PLE); tinham um histórico de participação, embora diferentes, em outros cursos de formação continuada e de contato com universidades. Além disso, eles eram professores efetivos, com mais de oito anos de experiência docente, e tinham o hábito de trabalharem e refletirem coletivamente na escola, inclusive na realização desses cursos que promoviam as mesmas reflexões e práticas sobre leitura para todas as disciplinas e trabalhavam sentidos presentes em documentos oficiais e em pesquisa no ensino de ciências.

As entrevistas, registradas em áudio e posteriormente transcritas, tiveram como base um roteiro semiestruturado previamente elaborado, composto por subitens na forma de questões que procuramos abordar em todas as quatro entrevistas realizadas. Esses subitens foram pautados a partir de três eixos principais: i) formação dos professores e a presença da leitura na sua formação; ii) participação dos professores nos cursos EMR e PLE, a partir de suas opiniões sobre o desenvolvimento desses cursos que enfocavam a leitura; iii) leitura na prática docente, em planejamento e utilização em sala de aula.

No entanto, cabe destacar que ocorreram pequenas variações nas perguntas formuladas e no encaminhamento das entrevistas, por mobilizarem diferentes memórias e estabelecerem diferentes relações e significações entre a entrevistadora e cada professor. Essa variação também é destacada por Almeida (2007) quando relata sobre o processo de construção das entrevistas realizadas em seu estudo. Em sua pesquisa, de modo semelhante ao nosso trabalho, a autora estabeleceu as questões básicas que compôs o roteiro semiestruturado, no entanto, admitiu as possíveis variações que ocorreriam entre as entrevistas em decorrência das respostas e das relações estabelecidas nessa situação.

Nesse sentido, a AD se mostrou uma ferramenta metodológica e analítica importante, uma vez que consideramos que os discursos analisados nesta pesquisa têm a entrevista como parte constituinte importante das condições de produção desses discursos, por considerar o contexto e os sujeitos nas análises.

Como estamos supondo que durante as entrevistas, expectativas, representações e tensões foram geradas, mobilizadas, atualizadas, como parte do mecanismo de antecipação, analiticamente, torna-se coerente considerar a relação de assimetria instaurada entre os interlocutores. Essa assimetria remonta a uma relação entre universidade-escola historicamente construída e que repercute nas formações imaginárias que podem presidir a troca de palavras entre os 
interlocutores, quanto às posições ocupadas, no momento das entrevistas, entre entrevistado, professor da escola, e entrevistador, pesquisadora vinculada a uma universidade. Tal relação também foi constatada e discutida em um trabalho anterior desenvolvido por Silva, Baena e Baena (2006). Esses lugares sociais devem ser considerados por interferir de maneira constitutiva nas respostas e até mesmo na construção oral das perguntas no momento de cada entrevista.

No entanto, lembramos que, do ponto de vista discursivo, sujeitos e sentidos se constituem simultaneamente e, portanto, não são esses lugares socialmente empíricos, de professor da escola básica e de professor ou pesquisadora da universidade, ocupados por entrevistados e entrevistadora, que constituem o funcionamento discursivo, já que discurso, para nós, é efeito de sentidos entre interlocutores, entre sujeitos. A passagem desse empírico para o discursivo propriamente dito se dá pelo funcionamento do mecanismo de antecipação. Esses lugares, assim, refletem imaginariamente (mas não automaticamente) em posições relativas entre os sujeitos no discurso. Do ponto de vista teórico que adotamos, não se trata de considerar a existência de uma influência "externa", de cunho sociológico, o que remeteria a papéis sociais, mas "interna" ao funcionamento discursivo, ou seja, constitutiva desse funcionamento, já que implicam em imagens entre locutores sem as quais não há interlocução.

A despeito da consideração dos lugares sociais dos sujeitos por outras abordagens teóricas e mesmo outras abordagens discursivas, mantemo-nos coerentes com a perspectiva teórico-metodológica da AD de origem francesa segundo trabalhos de Pêcheux e Orlandi, que tem como um de seus elementos teóricos fundamentais a noção de imaginário e a de sujeito como uma construção discursiva, possibilitada justamente pela existência desse imaginário.

Para a AD, o discurso não tem origem no sujeito. Trata-se de um processo em que se imbricam o simbólico e o histórico para constituir simultaneamente sujeitos e discursos. A ideia de que há um sujeito na origem dos discursos é o que Pêcheux chama de efeito ideológico elementar. É sobre efeito, e não sobre este ou aquele suposto conteúdo ideológico, que a $\mathrm{AD}$ trabalha.

Portanto, não é propriamente o ser professor, do lado do entrevistado, e o ser pesquisador (da universidade), do outro lado, segundo o ponto de vista teórico-metodológico que adotamos, que interferem na constituição desses discursos pelo mecanismo de antecipação. Acreditamos que a relação professor/escola de um lado e pesquisador/universidade de outro está associada a imaginários vinculados a ligações de poder que historicamente vêm organizando reciprocamente essas instituições e seus discursos: a escola, minimizada em seu valor social em comparação à produção do conhecimento na sociedade em que vivemos, relegada à sua reprodução, e a universidade, representada como efetiva instituição de produção de conhecimento legítimo, sejam conhecimentos pedagógicos ou conhecimentos sobre a natureza e sobre a sociedade.

Esse mecanismo está sempre presente em qualquer relação entre interlocutores reais e/ou virtuais, fazendo com que busquemos nos colocar na posição 
do outro para nos aproximarmos daquilo que "queremos" ouvir e/ou ler, ou do que "achamos" que o outro quer ouvir e/ou ler:

todo sujeito tem capacidade de experimentar, ou melhor, de colocar-se no lugar em que seu interlocutor "ouve" suas palavras. Ele antecipa-se assim a seu interlocutor quanto ao sentido que suas palavras produzem. Esse mecanismo regula a argumentação, de tal forma que o sujeito dirá de um modo, ou de outro, segundo o efeito que pensa produzir em seu ouvinte (ORLANDI, 2003, p. 39).

É assim, pelo mecanismo de antecipação, que podemos trabalhar com as posições discursivas e não as socialmente empíricas, ou seja, com a perspectiva de significação de onde fala aquele interlocutor e para onde projetamos uma suposta origem e, portanto, um suposto (mas uma suposição necessária) sujeito. É assim que dizemos que sujeito e sentidos se constituem simultaneamente.

Essa antecipação tem um funcionamento análogo ao do inconsciente, ou seja, se dá sem o controle consciente dos interlocutores, mas constitui igualmente o discurso desses sujeitos, no nosso caso, professores. Assim, durante as formulações das questões na entrevista, os professores podem ter atribuído sentidos, como de autoridade e de domínio de conhecimentos sobre leitura, à pesquisadora/entrevistadora, visto que ela estava desenvolvendo um trabalho de mestrado sobre esse assunto, ou podem ter partido do pressuposto de que ela falava (e pensava) do lugar daqueles que valorizam o ensino da leitura e o uso de textos em todas as disciplinas.

Por outro lado, a entrevistadora vinha de várias leituras sobre o tema de pesquisa e expectativas para a realização das entrevistas, influenciando a forma de elaboração das questões e seu próprio encaminhamento durante as entrevistas. Além disso, embora a entrevista tenha sido preparada, planejada previamente, a entrevistadora tinha uma relação muito próxima com esses professores, já os conhecia e convivia com eles semanalmente havia alguns meses, e por isso buscou aproveitar esse "clima" de amizade para desenvolver as questões. Isso resultou numa minimização ainda maior do controle consciente de suas formulações.

Desse modo:

na análise de sequências verbais, incluído aquelas obtidas em entrevistas como processos discursivos a serem analisados tendo em conta os aportes da análise de discurso mencionados, implica em buscar determinar as condições, ou seja, quem disse, para quem disse, quando disse e onde disse, considerando que as posições a serem analisadas são as imaginárias e não as concretas imediatas (ALMEIDA, 2007, p. 123).

Os dizeres da entrevistadora remetem a essa situação única, singular, na qual múltiplas expectativas e representações estavam em jogo. Entretanto, não consideramos um problema essa impossibilidade de controle sobre a situação da entrevista, já que nos pautamos em uma concepção de linguagem que não se refere unicamente à transmissão de informação, ou seja, a "extrair", durante as entrevistas, as informações dos professores, "o que eles quiseram dizerer" através de suas falas, para buscar a realidade por trás delas. A linguagem, dentro dessa 
perspectiva, não é vista como transparente, como se os sentidos dos professores sobre leitura fossem os mesmos em qualquer situação ou em qualquer relação. Porque é justamente aí, nesse "descontrole", que podemos apreender o funcionamento da ideologia, e, portanto, da exterioridade constitutiva, como contexto histórico-social mais amplo.

Dessa forma, consideramos que os sentidos, no nosso caso, sobre leitura na relação com a educação científica, foram produzidos em associação a essas condições de produção que compreendem tanto o contexto imediato quanto o mais amplo: o contexto histórico e social (ORLANDI, 1996).

Assim, para compreendermos os sentidos produzidos pelos professores no momento da entrevista, precisamos considerar que:

\begin{abstract}
quando se diz algo, alguém o diz de algum lugar da sociedade para outro também de algum lugar da sociedade e isso faz parte da significação. (...) É preciso dizer que todo discurso nasce de outro discurso e reenvia a outro, por isso não se pode falar em um discurso, mas em estado de um processo discursivo, e esse estado deve ser compreendido como resultando de processos discursivos sedimentados, institucionalizados. E finalmente, faz parte da estratégia discursiva prever, situar-se no lugar do ouvinte (antecipação das representações), a partir de seu próprio lugar de locutor, o que regula a possibilidade de respostas (ORLANDI, 1983, p. 19).
\end{abstract}

Mas, o discurso, mesmo não sendo só transmissão de informação, também produz esse efeito e tem sua função referencial. Alguns trechos dessas entrevistas foram utilizados como fontes de informações em vários momentos. Tais informações são, inclusive, importantes para a composição das condições de produção do discurso sobre leitura. Assim, conhecíamos a escola pelos olhos, experiências e discursos dos próprios professores entrevistados.

As análises que apresentamos, a título de exemplificação, compõem parte da dissertação de mestrado da primeira autora (ZIMMERMANN, 2008). Selecionamos trechos das análises dos discursos dos professores produzidos em entrevistas semiestruturadas que enfocaram um dos tópicos da pesquisa realizada, denominado "A leitura na formação dos professores". Na dissertação de mestrado, as análises estão organizadas em seis tópicos, na respectiva ordem: A leitura na formação dos professores; Fontes de leituras dos professores; A leitura e o livro didático; Modos de leitura; Relações entre leitura e o discurso científico; Relações discursivas entre leitura e contexto.

Para esse recorte da pesquisa, optamos por destacar o primeiro tópico, uma vez que as falas melhor exemplificam e problematizam o funcionamento do mecanismo de antecipação na sua relação com outros aspectos das condições de produção. E, ressaltamos, no que diz respeito à perspectiva discursiva adotada neste trabalho, que os “dados” analisados já são construções que resultaram de processos de interpretação, constituintes, em parte, de um gesto teórico (ORLANDI, 1996). Assim, “os dados são os discursos e estes não são objetos empíricos (...), mas dados construídos” (SILVA; BAENA; BAENA, 2006, p. 352). 
Os professores, ao relatarem sua formação e a relação da leitura com essa formação, mostraram alguns indícios de suas histórias de leitura que configuraram aspectos de seus imaginários sobre essa prática.

Um dos aspectos comuns que permeou as respostas dos professores sobre essa questão refere-se ao tom de justificativa em suas falas. Coerentemente com as ideias teóricas que apresentamos, buscamos compreender esse tom de justiticativa considerando a existência de representações e expectativas envolvidas na situação das entrevistas, uma vez que o foco era a leitura e a entrevistadora tem, como tema de sua dissertação, esse tema, ou seja, pode ser representada como especialista acadêmica em leitura. Seria pouco provável que não fosse gerado certo desconforto ao falar sobre esse tema num contexto histórico-social em que circulam sentidos e imagens do que seriam bons e maus leitores, em que a leitura tem a imagem de ser um hábito socialmente valorizado e, ao mesmo tempo, idealizado.

Essa valorização/idealização é discutida no trabalho de Chartier e Hébrard (1995) sobre os discursos sobre leitura na França entre o período de 1880 a 1980. Nesse estudo, os autores apontam que a posição da leitura foi alterada no espaço público, e que a partir da década de 1960 "tornou-se um gesto positivo" (p. 588). Nesse mesmo trabalho, os autores também colocam que esse sentido sobre leitura como um gesto positivo nem sempre existiu. A leitura adquiriu outras atribuições e posições para a sociedade em diferentes contextos históricos.

Lembramos que os discursos sobre a importância da leitura estão presentes desde o início de nossa trajetória escolar, constituindo imaginários sobre o tema nos quais essa prática também é colocada como necessária e valorizada na sociedade atual, e, simultaneamente, sobre nós mesmos como leitores, remetendo a um gesto de caráter positivo. O hábito de leitura aparece, muitas vezes, como um ideal o qual nunca atingimos.

Assim, a imagem da entrevistadora, na sua posição relativa às instituições em jogo no contexto imediato, se cruza com um imaginário que transcende fronteiras e remonta a toda uma história, e outros discursos.

Cada professor teve uma história de leitura diferente, que foi construída em lugares distintos, em relações e contextos diferentes. Buscamos, em alguns trechos das entrevistas, indícios dessas condições que constituíram esse imaginário.

215. E- (...) A leitura na tua formação...o que você costumava ler e se foi importante para a tua formação? 22. PG - Eu nunca tive o bábito da leitura... assim... evidente... não costumava ler... um pouco isso é meu... é da família... não lembro, assim, do meu pai lendo... a minha mãe fez até a $4^{a}$ série, meu pai até a $8^{a}$ (...) sempre tive dificuldade (...) mas a leitura, não lembro deles incentivarem... qual o contato que eu tive no Ensino Fundamental (...) não lembro da professora de português cobrando leitura... não lembro de ler o livro inteiro... no Ensino Médio também li muito pouco... Já na faculdade foi assim... por livre espontânea pressão... dai tinha que me desdobrar... na faculdade era onde eu tinha que ler mesmo e onde eu menos tinha tempo... tive que achar tempo para ler... estudava muito à noite... de sexta para sábado... de sábado para domingo... assim, eu tive o maior prazer com a leitura assim... 
A sequência da entrevista de PG se inicia com o relato da sua formação, que perpassa desde seu período escolar, buscando fatos anteriores ao início de sua graduação, inclusive o seu ambiente familiar daquela época. A palavra "formação" poderia ser interpretada de várias maneiras: formação acadêmica ou universitária, formação escolar, formação familiar. Na relação com a leitura, a palavra "formação" é significada remetendo ao papel da família.

Dessa forma, ele inicia justificando sua falta de hábito de leitura quase como um "ato errado", o que pode estar relacionado às expectativas desse professor relacionadas a uma autoavaliação como leitor a partir de uma imagem idealizada. E essa valorização/idealização da leitura também pode ser reforçada pela própria entrevistadora, no momento da formulação das questões nas entrevistas, em que utiliza palavras que remetem a essa conotação positiva da leitura, como no seguinte enunciado: "se foi importante para a tua formação".

Outras formulações possíveis, utilizadas nas entrevistas de PB ("de como a leitura fezparte da tua formação") e PP ("Vocêpodia contar um pouquinho da leitura na tua formação...”), e que se aproximam bastante, poderiam eventualmente mobilizar outros sentidos, o que de fato aconteceu, mas apenas em parte, na repetição deslocada dessa questão com a professora PB, que em sua fala busca justificar sua falta de hábito de leitura ("...lia muito pouco, sempre fui uma péssima leitura...sempre trabalhei e mesmo fazendo o curso continuei trabalhando para me sustentar...então eu não tinha disponibilidade..."), e com a professora PP, que relata seu gosto pela leitura desde criança, mas destaca as dificuldades com o português durante a escola ("Eu tive muita dificuldade com português, não com a língua, eu sempre gostei muito de ler..."). No entanto, essa relação direta da leitura com formação, e as possíveis justificativas do ser ou não (bom) leitor, não são evidenciadas na entrevista de PQ, em parte pela formulação mais geral sobre sua formação: “Fale um pouco sobre a sua formação...”. O que observamos, então, é que a leitura se restringiu aos sentidos sobre a prática escolar de PQ e os cursos de formação continuada.

Retomando a fala de PG, esse professor parece ter respondido de acordo com o que ele "achava", sem ter consciência disso, que a entrevistadora desejava ou não ouvir, ou seja, se colocando no lugar do outro, mas a partir de uma posição de significação sobre a leitura. Esse professor afirma que não possuía "hábito da leitura" durante sua trajetória escolar, relacionando esse hábito ao pouco incentivo familiar, inclusive buscando aspectos da própria formação escolar dos seus pais.

PG também relata que foi pouco incentivado no ambiente escolar, no qual não havia cobrança pela própria professora. Ao evidenciarmos esse relato, verificamos que o controle/cobrança e/ou incentivo seriam necessários para a construção de hábitos de leitura. Nessa fala, o professor atribui sentidos próximos entre incentivo e cobrança. Verificamos possíveis indícios de que ler, para esse professor, não é algo espontâneo, é preciso cobrar a leitura, incentivá-la.

Das formulações diferentes que a entrevistadora utilizou nesse tópico nas quatro entrevistas realizadas, a formulação para PB, como já indicado anteriormente, não difere tanto da formulação para a PG. Entretanto, PB, diferentemente 
de PG, cuja fala remete "formação" a família, iniciou seu relato sobre sua formação considerando o período após a sua entrada na faculdade, não mencionando aspectos sobre o período escolar e sobre o âmbito familiar. Esse não dito está relacionado com o modo de significação da palavra "formação" na resposta da professora, atribuindo um sentido vinculado à formação inicial (graduação) e continuada (aperfeiçoamento).

Mas, do mesmo modo como apareceu nas outras entrevistas, essa professora justifica a ausência de "bábito de leitura". Essas justificativas se pautaram na questão do tempo, nas condições financeiras e na própria qualidade do curso de graduação em que se formou. Nessa fala, PB relata com angústia esse período. Sua posição é bastante diferente das falas motivadoras de PG sobre essa época da graduação:

9. E-Então... em cima do que você falou sobre leitura... fala um pouquinho sobre a tua formação... de como a leitura fez parte da tua formação...

10. PB - (...) Eu entrei em $74 \ldots$ me formei em $77 . .$. só que nesse periodo, para você ter noção, Ciências Biológicas foi o pior ensino que eu acho que teve em toda época. Eu tive uma formação, assim, péssima, eu ficava comparando muito com o que eu tive no Ensino Médio... parecia que eu sabia muito mais... aquilo foi me frustrando... me formei praticamente sem ter uma formação direito (...) lia muito pouco, sempre fui uma péssima leitora... sempre trabalhei e mesmo fazendo o curso continuei trabalhando para me sustentar... então, eu não tinha disponibilidade... não tinha condições financeiras para fazer muita coisa... bom... mas en tinha uma coisa que era legal, eu sempre quis dar aula... então, como você faz.para dar aula quando você não sabe o que vai dar? Tem que ir atrás... então, eu fui buscar informação daquilo que era importante para mim no começo...

O interessante no discurso de PB é seu envolvimento com a leitura em sua prática escolar. $\mathrm{Na}$ incompletude da formação por ela relatada, a professora teve que buscar informações. A fala de PB relaciona a leitura, no sentido de busca de informações, com a sua formação após o término da graduação, referente à sua prática, como professora atuante. Trata-se de leitura para aprender conteúdos de Biologia que ela significa como "buscar informação". Essa relação estabelecida entre leitura e formação, já atuando como professora, também foi relatada em outro trabalho sobre discursos de professores sobre leitura desenvolvido pelas autoras Andrade e Martins (2006).

$\mathrm{Na}$ continuação da entrevista de PB, após alguns relatos sobre sua trajetória docente, emergiram outros aspectos sobre leitura e formação. Nessa fala, vemos alguns indícios em relação ao imaginário de leitura, principalmente quanto à formação do sujeito-leitor e como essa professora significa um bom leitor nesse momento/situação.

27. E - Então, vamos falar um pouquinho da leitura... como ela aparece na tua prática, como ela foi surgindo... 28. PB - Eu não sou uma pessoa boa para ler até hoje... eu tenho as minhas dificuldades...

(...) 30. PB - Mas hoje... eu gostaria de ser assim... uma pessoa... por exemplo, meu marido é uma pessoa que lê muito, ele lê e discursa muito sobre a leitura, eu não gosto e nem sei fazer isso... tenho uma dificuldade imensa, meu marido devora livros, "O Mundo de Sofia" ele devorou (...) e eu só consigo ler aquilo que me interessa muito... e só o que me interessa é o que está na minha área... é isso que me irrita... eu deveria gostar de outras coisas... e isso é falta de hábito... eu deveria ter tido lá atrás e eu não tive... 
Não interpretamos como intencionais essas relações estabelecidas por PB sobre hábito de leitura e a pergunta colocada, pois o que buscamos compreender com essa perspectiva de análise de discurso são justamente os aspectos das produções discursivas cujos controles escapam da intencionalidade e da consciência dos sujeitos. O objetivo da entrevistadora com a questão era que a professora narrasse sobre a leitura na sua prática em sala de aula, que ela falasse como essa prática acontecia. Diferentemente do modo como a formulação da questão foi significada pela professora, não pretendíamos julgar se PB era uma boa leitora, ou ainda, se tinha o hábito de leitura. Contudo, PB inicia sua resposta justificando sua dificuldade. Nesse caso, fica evidente como são grandes as tensões envolvidas entre a entrevistadora e a entrevistada, mais um indicativo da influência das expectativas envolvidas no momento da entrevista.

Assim, ao interferir na questão (turno 27), a entrevistadora buscou explicitar seu caráter não avaliativo, buscando, agora sim, conscientemente, controlar o sentido de sua questão. Mas, da mesma forma como acontece na primeira resposta, a professora elaborou sua fala a partir desse imaginário do que seria um bom leitor. Para tanto, ela buscou a referência do marido como um bom leitor, por considerar que ele lê de tudo. Ao apontar isto, a professora justifica novamente sua "dificuldade". Nesse momento, PB se colocou na posição de esposa, não mais de professora, utilizando como exemplo a relação do marido com a leitura, sobre a qual possivelmente construiu uma imagem de leitor ideal. É importante colocar que essa imagem de mau leitor pode estar atrelada à sua formação inicial, bastante deficitária de acordo com sua fala ao longo da entrevista.

Em um dos trabalhos realizados por Ricon e Almeida (1991), os autores explicitam outro sentido sobre o que poderia ser considerado um bom leitor quando colocam: "Bom leitor, o estudante continuará mais tarde, já fora da escola, a buscar informações necessárias à vida de um cidadão, a checar notícias, a estudar, a se aprofundar num tema, ou simplesmente, a se dedicar à leitura pelo prazer de ler" (p. 9).

Se partirmos dessa perspectiva, poderíamos considerá-la uma boa leitora, uma vez que, ao verificarmos as falas produzidas em outros momentos na sua entrevista, evidenciamos sua preocupação constante pela busca de informação, pelo envolvimento em atividades que acrescentem à sua prática docente e a seu conhecimento, por meio de participações em projetos, cursos, disciplinas, como aluno especial (retorno ao ambiente universitário), tanto da graduação, como da pós-graduação.

Outros sentidos estão em jogo sobre essa relação de leitor ideal. E se observarmos essa fala da professora, esta está relacionada com outros discursos sobre leitura, construindo um imaginário de um leitor ideal ou bom leitor que parece se materializar na imagem que ela construiu do marido. No entanto, o sentido sobre leitura ideal dessa professora parece estar associado também ao tipo de leitura, uma leitura que ela considera "não leitura". Seriam leituras que não estão relacionadas com a sua área. Parece haver uma leitura legítima. E isso se refere à sua memória discursiva. “'O que é que eu leio que mereça ser declarado?’ Isto é: 
‘o que é que eu leio de fato de literatura legítima?’ E o que ele responde, não é o que escuta ou lê verdadeiramente, mas o que lhe parece legítimo naquilo que lhe aconteceu de ter lido" (BOURDIEU; CHARTIER, 2001, p. 236).

Essa memória, essa imagem de leitura ideal, de alguma forma não permite que leituras relacionadas, por exemplo, à ciência e à sua área de atuação profissional, como o livro de Bruno Latour ou textos de divulgação científica citados por PB, como textos de Dráuzio Varela, em outros momentos durante sua entrevista, sejam consideradas tão legítimas quanto leituras de clássicos literários ou o que a indústria editorial chama de "best sellers", como é o caso do "O mundo de Sofia", livro que o marido estava lendo, parte de seu exemplo como bom leitor. A leitura na área científica adquire um papel diferente no imaginário dessa professora na formação do sujeito-leitor, considerada como não ideal. Por isso, talvez se explique a retomada constante das justificativas. A leitura estaria relacionada apenas com o literário ou com a cultura geral e não com o científico, no sentido de informativo ou o especializado.

\section{CONSIDERACְÕES FINAIS}

Quando realizamos as entrevistas, sentidos sobre a leitura no ensino de ciências já estavam presentes, circulavam em nossa sociedade, possuíam suas histórias. Principalmente, discursos que a tomam como algo valorizado, considerado como componente de todas as disciplinas escolares, inclusive as de ciências e não só das de linguagens ou humanidades. Discursos que idealizam imagens de "bom leitor". Discursos que significam os aspectos que interfeririam na formação de "bons leitores". Nessa perspectiva, um dos aspectos importantes que foi apontado na fala dos professores, refere-se às suas histórias de leitura. O imaginário de leitura desses professores relaciona a leitura com a história familiar e escolar, como colocado por mais de um professor nas entrevistas. Eles significaram a leitura a partir de suas memórias enquanto leitores, sendo a prática de leitura apresentada pelos professores por um viés positivo. Esses dizeres e outros impõem imaginariamente modos como os professores "devem" desenvolver suas práticas e se relacionar com a leitura.

Dessa forma, ao pressupor que esses discursos dos professores foram produzidos numa situação de entrevista em que sentidos sobre a leitura estavam em jogo, conformando expectativas e representações entre entrevistado, na posição de professor de uma escola pública, e entrevistadora, na posição de pesquisadora da área de ensino de ciências que estava desenvolvendo um trabalho acadêmico sobre leitura, e, portanto, significando que se tratava de algo importante e possivelmente valorizado, pudemos compreender melhor algumas falas produzidas pelos professores nas entrevistas. Além de compreender os discursos, relacionados a essas falas, como produzidos num cruzamento entre o contexto imediato e local e o histórico-social mais amplo. 
Em relação às expectativas e representações, essas mobilizaram dizeres que se aproximavam ao que eles imaginavam que a entrevistadora gostaria de ouvir, antecipando-os nas respostas. Antecipação que só é possível porque já há sentidos e, portanto, o processo que estamos analisando, enquanto discurso, não tem origem naquele momento, coincidentemente com aquelas falas. Assim, a situação da entrevista apareceu como um aspecto das condições de produção dos discursos analisados, tendo o mecanismo de antecipação uma contribuição importante para a configuração das análises desta pesquisa, justamente nessa ligação entre contexto imediato e contexto histórico-social mais amplo.

Com isso, defendemos que ao trazer noções que permitem trabalhar a opacidade da linguagem (quando não a atravessamos para encontrar uma realidade verdadeira atrás dela) estamos proporcionando outras relações e compreensões do papel da entrevista na pesquisa e, consequentemente, dos “dados" produzidos nesse processo. Apontando, principalmente, a própria entrevista como participante da produção dos "dados" analisados, à medida que ela trabalha memórias discursivas (sentidos já existentes), relações de força e de sentidos.

Não se trata de retirar unicamente as informações produzidas nas entrevistas, "enquanto dados que revelariam uma verdade transparente" (ALMEIDA, 2007, p. 129), na qual reafirmaríamos expectativas de nossas pesquisas e leituras. Trata-se de entender de que forma essas informações foram construídas, problematizando a complexidade do funcionamento da linguagem nessa relação entre entrevistado e entrevistador e dos processos de significações desencadeados e compreendidos como de natureza histórico-social. A informação passa a ter outro valor a partir dessa perspectiva discursiva que, ao considerar o discurso como efeito de sentidos entre locutores, considera que uma imagem do outro, sócio-historicamente produzida, está presente em qualquer produção de linguagem, sendo constitutiva dessa produção.

\section{NOTAS}

1 Trabalho realizado com o auxílio financeiro da Coordenação de Aperfeiçoamento de Pessoal de Nível Superior.

${ }^{2}$ Orlandi (1994) destaca o papel do imaginário como produtor do efeito da linguagem como transparente. Nesse sentido, a autora aponta que a relação entre a linguagem e o mundo não é direta, "mas funciona como se fosse, por causa do imaginário” (p. 57-58). Para maiores aprofundamentos sobre essa noção, sugerimos a leitura de Orlandi (1994).

${ }^{3}$ Compreendemos "relações de força" como elementos exteriores ao discurso, próprios da formação social em questão. Remete ao pressuposto de que em toda sociedade há relações de poder que fazem parte das condições de produção dos discursos.

${ }^{4}$ Grifos nossos. 
${ }^{5}$ A numeração à frente das falas se refere à sequência dos turnos das entrevistas. $\mathbf{E}$ se remete à fala

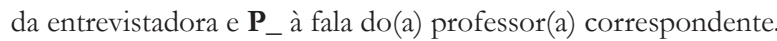

\section{REFERÊNCIAS BIBLIOGRÁFICAS}

ALMEIDA, M. J. P. M. Entrevista e representação na memória do ensino de Ciências: uma relação com a concepção de linguagem. In: R. NARDI (Ed.) A pesquisa em Ensino de Ciências no Brasil: alguns recortes. São Paulo: Escrituras, 2007, p. 117-130.

ANDRADE, I. B; MARTINS, I. Discursos de professores de ciências sobre leitura. Investigações em Ensino de Ciências, Porto Alegre, v.11, n.2, p. 121-151, 2006. Disponível em: < http://www.if.ufrgs. br/ienci/artigos/Artigo_ID148/v11_n2_a2006.pdf> Acesso em: 01 mar, 2013.

BOURDIEU, P; CHARTIER, R. A leitura: uma prática cultural. In: R. CHARTIER (Ed.). Práticas da leitura. $2^{a}$ ed. São Paulo: Estação Liberdade. 2001.

CASSAB, M.; MARTINS, I. Significações de professores de ciências a respeito do livro didático. Ensaio - Pesquisa em Educação em Ciências, Belo Horizonte, v.10, n.1, p.1-24, 2008. Disponível em: <http://www.portal.fae.ufmg.br/seer/index.p hp/ensaio/article/viewFile /144/193> Acesso em: 01 mar, 2013.

CHARTIER, A.; HÉBRARD, J. Discursos sobre a leitura: (1880-1980). São Paulo: Ática, 1995.

FLÔR, C. C; SOUZA, S. C. Quando o dizer de um sujeito é objeto de pesquisa: contribuições da Análise do Discurso Francesa para a compreensão da fala de professores em situação de entrevista. Ensaio - Pesquisa em Educação em Ciências, Belo Horizonte, v.10, n.1, p.1-16, 2008. Disponível em: <http://www.portal.fae.ufmg.br/seer/index.php/ensaio/article/view/141/201> Acesso em: 28 fev, 2013.

FOUCAULT, M. A ordem do discurso. 10 a ed. Rio de Janeiro: Loyola, 2004.

GIRALDI, P. M; SOUZA, S. C. O funcionamento de analogias em textos didáticos de Biologia: questões de linguagem. Ciência \& Ensino,Campinas, v.1, n.1, p. 9-17, 2006. Disponível em: < http:// www.ige.unicamp.br/ojs/index.php/cienciaeensino/article/

viewFile/34/92> Acesso em: 01 mar, 2013.

MARTINS, I. Analisando livros didáticos na perspectiva dos Estudos de Discurso: compartilhando reflexões e sugerindo uma agenda para a pesquisa. Pro-Posições, Campinas, v.17, n.1(49), p.117136, 2006. Disponível em: <http://www.proposicoes.fe.unicamp.br/ proposicoes/textos/49_ dossie_martinsi.pdf > Acesso em: $28 \mathrm{fev}, 2013$.

MARTINS, I.; NASCIMENTO, T. G.; ABREU, T. B. Clonagem na sala de aula: um exemplo do uso didático de um texto de divulgação científica. Investigações em Ensino de Ciências, Porto Alegre, v.9, n.1, p.95-111, 2004. Disponível em: < http://www.if.ufrgs.br/ienci/artigos/Artigo_ID111/ v9_n1_a2004.pdf> Acesso em: 01 mar, 2013.

MONTEIRO, I. G.; JUSTI, R. S. Analogias em livros didáticos de Química brasileiros destinados ao Ensino Médio. Investigações em Ensino de Ciências, Porto Alegre, v.5, n.2, p.67-91, 2000. Disponível em: <http://www.if.ufrgs.br/ienci/artigos/Artigo_ID59/v5_n2_a2000.pdf> Acesso em: 28 fev, 2013.

MORAES, R. Uma tempestade de luz: a compreensão possibilitada pela análise textual discursiva. Ciência \& Educação, São Paulo, v.9, n.2, p.191-211, 2003. Disponível em: <http://www.scielo.br/ pdf/ciedu/v9n2/04.pdf> Acesso em: 01 mar, 2013.

MORTIMER, E. F.; SCOTT, P. Atividade discursiva nas salas de aula de ciências: uma ferramenta sociocultural para analisar e planejar o ensino. Investigação em Ensino de Ciências, Porto Alegre, v.7, n.3, p.283-306, 2002. Disponível em: < http://www.if.ufrgs.br/ienci/artigos/Artigo_ID94/v7_ n3_a2002.pdf $>$ Acesso em: 28 fev, 2013.

ORLANDI. E. P. A linguagem e seu funcionamento: as formas do discurso. São Paulo: Brasiliense,1983.

Discurso, imaginário social e conhecimento. Em Aberto, Brasília, v. 14, n. 61, p. 53-59, 1994. Disponível em: <http://www.rbep.inep.gov.br/index.php/emaberto/article/ viewFile/911/817> Acesso em: 30 jan, 2014. 
Interpretação: autoria, leitura e efeitos do trabalho simbólico. Petrópolis: Vozes, 1996. Análise de discurso: Princípios e procedimentos. $5^{\text {a }}$ ed. Campinas: Pontes, 2003.

PÊCHEUX, M. Análise automática do discurso (AAD-69). In: GADET, M e HAK, F (Ed.). Por uma análise automática do discurso: uma introdução à obra de Michel Pêcheux. $2^{a}$ ed. Campinas: Pontes, 1993. . O discurso: estrutura ou acontecimento. $2^{\mathrm{a}}$ ed. Campinas: Pontes, 1997.

RAMOS, M. B.; LINSINGEN, I. V.; CASSIANI, S. Ciência e tecnologia no Jornal Nacional um exercício de análise discursiva para se pensar o trabalho da linguagem televisiva em aulas de ciências. In: JORNADAS LATINO-AMERICANAS DE ESTUDOS SOCIAIS DAS CIÊNCIAS E DAS TECNOLOGIAS, 7., 2008. Rio de Janeiro. Atas... Rio de Janeiro: DCC-IM/NCJ - UFRJ, p. 1-24, 2008. Disponível em: <http://www.necso.ufrj.br/esocite2008/resumos/36311.htm> Acesso em: 28 fev, 2013.

RICON, A. E.; ALMEIDA, M. J. P. M. Ensino da Física e Leitura. Leitura: Teoria \& Prática, Campinas, v.10, n.18, p.7-16, 1991.

SEPULVEDA, C. A. S. E.; EL-HANI, C. N. Apropriação do discurso científico por alunos protestantes de Biologia: uma análise à luz da teoria da linguagem de Bakhtin. Investigações em Ensino de Ciências, Porto Alegre, v.11, n.1, p.29-51, 2006. Disponível em: <http://www.if.ufrgs.br/ienci/ artigos/Artigo_ID143/v11_n1_a2006.pdf> Acesso em: 28 fev, 2013.

SILVA, H. C.; ALMEIDA, M. J. P. M. O deslocamento de aspectos do funcionamento do discurso pedagógico pela leitura de textos de divulgação científica em aulas de física. Revista Electrónica de Enseñanza de las Ciencias, Vigo, v.4, n.3, p.1-25, 2005. Disponível em: <http://reec.uvigo.es/ volumenes/volumen4/ART8_Vol4_N3.pdf> Acesso em: 28 fev, 2013.

SILVA, H. C.; BAENA, C. R.; BAENA, J. R. O dado empírico de linguagem na perspectiva da análise de discurso francesa: um exemplo sobre as relações discursivas entre ciência, cotidiano e leitura. Ciência \& Educação, São Paulo, v.12, n.3, p. 347-364, 2006. Disponível em: < http:/ /www.scielo.br/ pdf/ciedu/v12n3/08.pdf> Acesso em: 11 fev, 2014.

ZIMMERMANN, N. Leitura e ensino de Ciências/ Geociências: algumas condições de produção do imaginário e discurso dos professores. 2008. 163 f. Dissertação de (Mestrado em Ensino e História de Ciências da Terra) - Instituto de Geociências, Universidade Estadual de Campinas, Campinas, 2008.

Data Recebimento: 26/03/2013

Data Aprovação: 24/01/2014

Data Versão Final: 12/05/2014

\section{Contato:}

Universidade Federal de Santa Catarina. Departamento de Metodologia de Ensino - CED/UFSC - $1^{\circ}$ andar - bloco B - Campus Universitário - Trindade - Florianópolis, SC - Brasil

Caixa Postal: 476

CEP: $88040-900$ 
